\title{
Phosphogypsum recycling into inorganic dyes
}

\author{
Nina Shabelskaya ${ }^{1, *}$, Roman Medvedev ${ }^{1}$, Yuliya Gaidukova ${ }^{1}$, and Marina Astachova ${ }^{1}$ \\ ${ }^{1}$ Platov South-Russian State Polytechnic University (NPI), Novocherkassk, Russian Federation
}

\begin{abstract}
Currently, chemical wastes recycling into valuable secondary products poses a pressing challenge. During phosphoric acid production from apatite raw materials, large-tonnage phosphogypsum wastes are formed, resulting in ecosystem dysfunction. Besides, such wastes occupy significant production areas. Calcium sulfate is the main component of phosphogypsum. The paper addresses the possibility of phosphogypsum reduction to calcium sulfide, which has the capacity for luminescence under UV-light. Charcoal, sucrose, and citric acid were used as reducing agents. The obtained inorganic luminescent dyes were examined using X-ray phase analysis, scanning electron microscopy (SEM), and electron probe microanalysis (EPMA). It was found that, in the presence of charcoal, the process is accompanied by an uneven distribution of calcium sulfide over the volume of the system and, as a consequence, an uneven glow of the sample. The use of citric acid and sucrose as reducing agents results in the synthesis of samples with a uniform glow. The efficiency of the calcium sulfate conversion to calcium sulfide is 51$58 \%$. A mechanism of calcium sulfate reduction is proposed. The obtained results can serve as a basis for the development of a technology for the recycling of large-tonnage phosphoric acid production wastes into cheap and much-needed inorganic luminescent dyes.
\end{abstract}

\section{Introduction}

During phosphoric acid production from apatite raw materials, large-tonnage phosphogypsum wastes are formed, resulting in ecosystem dysfunction [1, 2]. Besides, such wastes occupy significant production areas $[1,3]$. Currently, chemical wastes recycling into valuable secondary products poses a pressing challenge. With the depletion of mineral deposits, it becomes necessary to develop new waste recycling technologies. Within this context, phosphogypsum can be classified as a mineral associated with no extraction costs. These factors determine a strong interest among researchers in the challenges of studying phosphogypsum properties and ways of phosphogypsum recycling [4-9]. One of the forms of phosphogypsum recycling is its reuse for the production of building materials, i.e. wall panels, dry mixes, etc. [10-12], and various types of cement [1315]. However, phosphogypsum cannot be used on an industrial scale due to its high acidity. The removal of residual acid is energy-consuming and economically impractical. Phosphogypsum is also used for soil improvement [16-19]. But such form of its recycling leads to uncontrolled land pollution with impurities contained in phosphogypsum. Besides, such use of phosphogypsum - a valuable raw material for the production of some major inorganic substances, such as calcium carbonate [20-22], calcium sulfoaluminate [23], lithium sulfate monohydrate, calcium sulfate [22], and lime [24] — is economically impractical.

In the paint and varnish industry, inorganic fillers imparting specific properties (improvement of strength and aesthetic characteristics) to finished products are widely used. Sometimes, inorganic fillers are introduced into polymers to reduce the cost of products. As a rule, fillers are incorporated into the composition in the amount of up to $10 \mathrm{wt} \%$. Synthesis of luminophores is one of the rapidly growing directions in developing new fillers. Based on luminophores, it is possible to develop dyes to be used in the paint and varnish industry, production of polymer compounds, decoration of clothing and various objects. Silicates, phosphates, sulfides and other compounds can be used as luminescent materials. Zinc, barium, calcium and cadmium sulfides activated by copper, silver, rare earth elements are applied in industrial setting. Among the most commonly used luminophores, calcium sulfide can be mentioned [25, 26]. Therefore, the purpose of the study was to develop a method to obtain an inorganic luminescent dye from phosphoric acid production wastes.

\section{Methods}

Phosphogypsum for agriculture with a calcium sulfate dihydrate $\left(\mathrm{CaSO}_{4} \cdot 2 \mathrm{H}_{2} \mathrm{O}\right)$ content of $99 \mathrm{wt} \%$ was used as a starting material. Sucrose $\left(\mathrm{C}_{12} \mathrm{H}_{22} \mathrm{O}_{11}\right)$, birch charcoal

\footnotetext{
* Corresponding author: nina shabelskaya@mail.ru
} 
(C), and citric acid $\left(\mathrm{C}_{6} \mathrm{H}_{8} \mathrm{O}_{7}\right)$ were used as reducing agents.

The initial phosphogypsum had a moisture content of $14 \mathrm{wt} \%$. It was pre-dried in an electric drying oven at a temperature of $100^{\circ} \mathrm{C}$ to a moisture-free weight.

The initial substances - phosphogypsum and reducing agents - were weighed with an accuracy of $0.01 \mathrm{~g}$ using an electronic balance, homogenized in a mixer (power: $0.45 \mathrm{~kW}$; speed: $1500 \mathrm{rpm}$ ) for 30 seconds, placed in alundum crucibles and put into a muffle furnace to be heat-treated according to the established temperature-time cycle, including heating to $140^{\circ} \mathrm{C}$ for 30 minutes, holding for 30 minutes, heating to $800^{\circ} \mathrm{C}$ for 30 minutes, holding for 60 minutes, and slow cooling together with the furnace to room temperature.

The phase composition of the calcined samples was determined using an ARL X'TRA X-ray diffractometer (Cu-Ka radiation was used). Micrographs of the samples and material composition were examined using scanning electron microscopy (SEM) and electron probe microanalysis (EPMA).

Photographs of the samples were taken under incandescent light or UV-light emitted by a luminescent Camelion FT5 BLACK LIGHT lamp.

\section{Results and Discussion}

During phosphogypsum drying, physically bound water is removed. The process is accompanied by changes in phosphogypsum color from pale gray to white (whiteness increases by approximately 10\%).

Phosphogypsum calcination results in the loss of chemically bound water according to the following equation:

$$
\mathrm{CaSO}_{4} \cdot 2 \mathrm{H}_{2} \mathrm{O}=\mathrm{CaSO}_{4}+2 \mathrm{H}_{2} \mathrm{O} .
$$

As a result of the reaction, calcium sulfate passes into the anhydrous state. Depending on the temperature conditions of the process, the dehydration reaction can be reversible or irreversible. If the heat treatment temperature is not high enough (usually not exceeding $500^{\circ} \mathrm{C}$ ), calcined calcium sulfate can capture crystallization water molecules, first converting to calcium sulfate hemihydrate $\mathrm{CaSO}_{4} \cdot 0.5 \mathrm{H}_{2} \mathrm{O}$, and then - to calcium sulfate dihydrate $\mathrm{CaSO}_{4} \cdot 2 \mathrm{H}_{2} \mathrm{O}$. Calcination at a temperature of $800^{\circ} \mathrm{C}$ is accompanied by the formation of a product that is not capable to absorb crystallization water. If the calcination temperature is high (above $1000^{\circ} \mathrm{C}$ ), calcium sulfate can capture water molecules.

To obtain anhydrous calcium sulfate, phosphogypsum was heat-treated at a temperature of $800^{\circ} \mathrm{C}$ for an hour. A radiograph of the calcined phosphogypsum sample is shown in Figure 1a. As seen in Figure 1a, the sample is presented by calcium sulfate (PDF No. 010-71-4906). The weight loss of the samples was $20-21 \mathrm{wt} \%$.

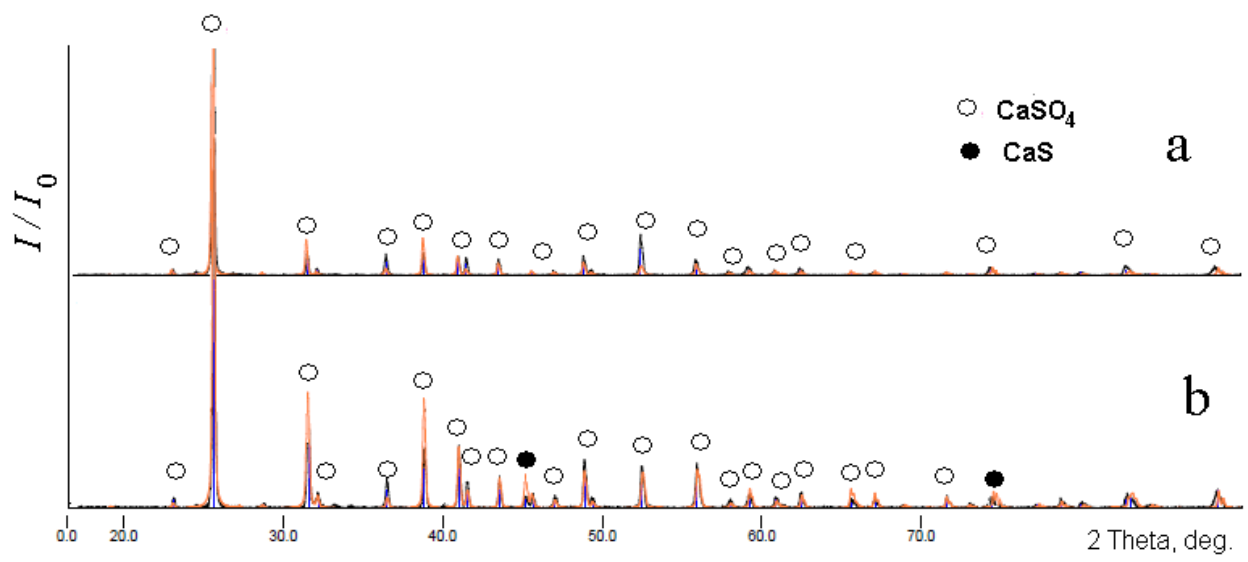

Fig.1. Radiographs of phosphogypsum samples: (a) dried, (b) calcined with a reducing agent

After the heat treatment in the presence of a reducing agent, according to radiographs (Figure 1b), the samples represented a mixture of calcium sulfate and calcium sulfide (PDF No. 010-75-0261).

During the heat treatment, the reaction of the reduction of calcium sulfate to calcium sulfide supposedly takes place:

$$
\mathrm{CaSO}_{4}+2 \mathrm{C}=\mathrm{CaS}+2 \mathrm{CO}_{2} \text {. }
$$

The efficiency of the calcium sulfate conversion to calcium sulfide under the action of different reducing agents was as follows (wt\%): 57.9 - for charcoal, 54.0 — for citric acid, 51.4 - for sucrose.

The sample is formed by lamellar crystals, on the surface of which smaller particles of irregular shape are located. Figure 2 shows a micrograph of the sample as an example (citric acid was used as a reducing agent). 


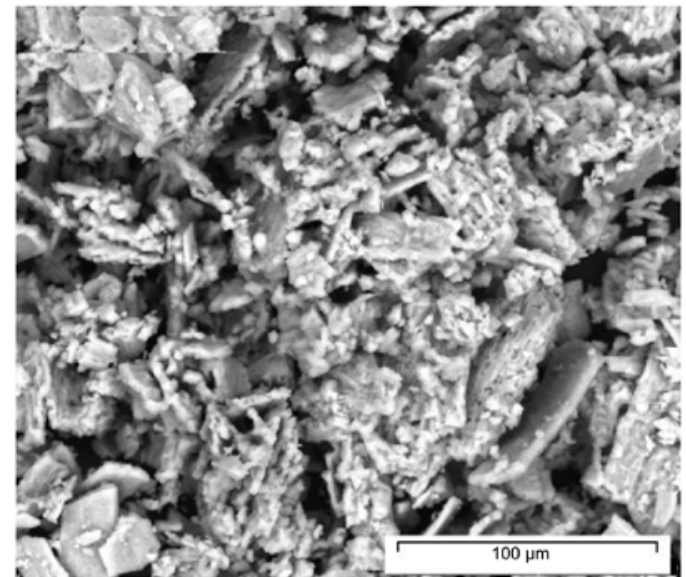

Fig.2. Micrograph of a phosphogypsum sample (reducing agent — citric acid)

Figure 3 presents the results of elemental analysis. According to those results, the lamellar crystals correspond to the unreduced calcium sulfate $\mathrm{CaSO}_{4}$ in terms of their chemical composition.

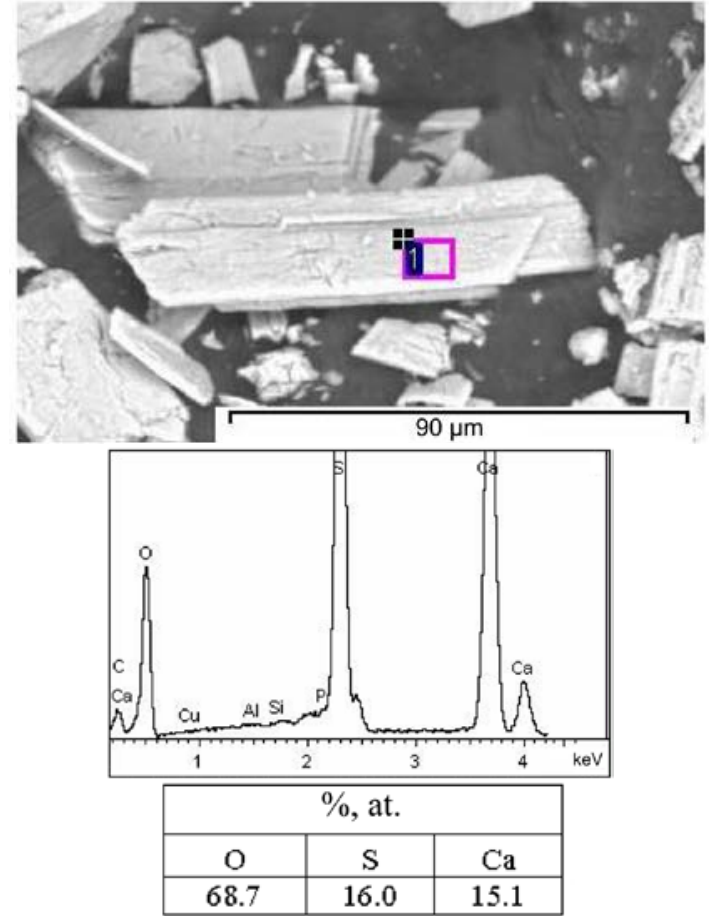

Fig.3. SEM-image of the synthesized material

In the course of the study, it was found that phosphogypsum, heat-treated in the presence of reducing agents, has the capacity for luminescence conditioned by the presence of calcium sulfide. Figure 4 shows photos of the samples under visible light (Figure 4a-c) and UVlight (Figure 4d-f). Charcoal (a, d), citric acid (b, e), and sucrose (c, f) were used as reducing agents.

In the presence of charcoal as a reducing agent, the reaction product is represented by separate areas with a bright glow in UV-light. When oxygen-containing reducing agents (sucrose or citric acid) were used, the glow was weaker.

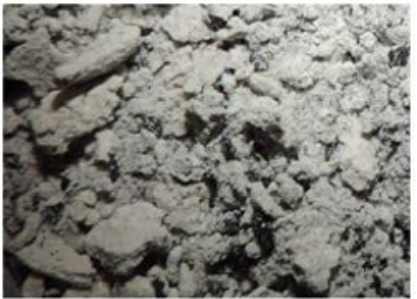

a

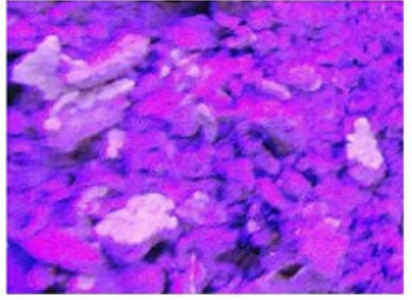

d

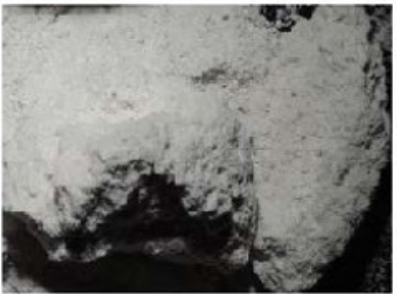

b

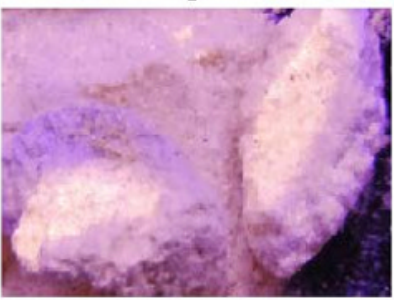

e

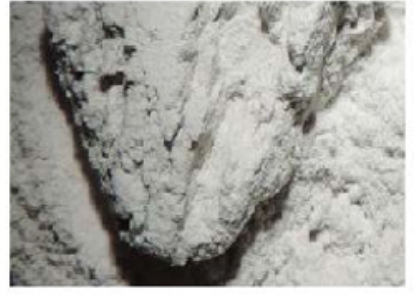

$\mathrm{C}$

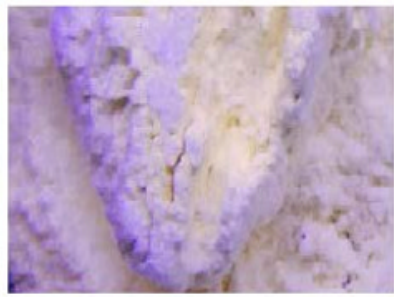

$\mathrm{f}$

Fig.4. Samples of reduced phosphogypsum under: (a-c) ordinary light, (d-f) UV-light. Reducing agent: (a, d) charcoal; (b, e) citric acid; (c, f) sucrose

If charcoal is used, reduction regions are distributed unevenly. This may be due to the uneven distribution of the reducing agent over the sample volume and heterogeneous nature of the process. If oxygencontaining reducing agents (citric acid or sucrose) are used, the glow is evenly distributed over the sample 
volume. Such a distribution pattern of calcium sulfide, which has properties of a luminophore material, can be associated with the melting of citric acid (melting point $-153^{\circ} \mathrm{C}$ ) and sucrose (melting point $-186^{\circ} \mathrm{C}$ ) as well as even distribution of the reducing agent over the sample volume.

Thus, the possibility of phosphogypsum recycling into an inorganic luminescent dye based on calcium sulfide was studied. The obtained results can serve as a basis for the development of a technology for the recycling of large-tonnage phosphoric acid production wastes into cheap and much needed inorganic luminescent dyes.

\section{Conclusions}

1. The possibility and conditions for the production of inorganic luminescent dyes (based on calcium sulfide) from phosphogypsum were determined.

2. The process of the reduction of calcium sulfate (the main component of phosphogypsum) to calcium sulfide under the influence of different reducing agents (charcoal, citric acid, sucrose) was shown.

3. It was found that the process with the use of charcoal as a reducing agent is accompanied by the formation of a material where calcium sulfide is unevenly distributed over the sample volume, which may be due to the uneven contact between phosphogypsum and the reducing agent. In the presence of citric acid or sucrose, the glow is evenly distributed over the surface of the sample.

\section{References}

1. J.P. Xu, L.R. Fan, Y.C. Xie, G. Wu, Journ. of Cleaner Production. 215, 175 (2019)

2. N.A. Golubkina, V.E. Mironov Geochemistry International 5, 12, 1263 (2018)

3. R. El Zrelli, L. Rabaoui, H. Abda, N. Daghbouj, R. Perez-Lopez, S. Castet, T. Aigouy, N. Bejaoui, P. Courjault-Rade Journal of hazardous materials. 363, 258 (2019)

4. R. Millan-Becerro, R. Perez-Lopez, F. Macias, C.R. Canovas, E.M. Papaslioti, M.D. Basallote Science Of The Total Environment 660, 395 (2018)

5. X.B. Li, Q. Zhang, Z.H. Shen, L.J. Li, X.H. Li, S. Mao Journal Of Crystal Growth 511, 48 (2019)

6. G. Gaidajis, A. Anagnostopoulos, A. Garidi, E. Mylona, I.E. Zevgolis Environmental Geotechnics 5, Is. 6310 (2018)

7. P. Kuzmanović, N. Todorović, S. Forkapić, L.F. Petrović, J. Knežević, J. Nikolov, B. Miljević Radiation Physics and Chemistry 166, 108463 (2020)

8. L. Plyatsuk, M. Balintova, Y. Chernysh, I. Ablieieva, O. Ablieiev Lecture Notes in Mechanical Engineering 843 (2020)

9. B. Wang, G. Lian, X. Lee, B. Gao, L. Li, T. Liu, X. Zhang, Y. Zheng Chemosphere 238, 124684 (2020)
10. P. Szajerski, J. Celinska, H. Bern, A. Gasiorowski, R. Anyszka, P. Dziugan Construction and building materials 198, 390 (2019)

11. E. Miekos, M. Zielinski, K. Kolodziejczyk, M. Jaksender Road materials and pavement design 20, 2 440 (2017)

12. J. James Revista facultad de ingenieria, universidad pedagogica y tecnologica de Colombia 28, 5044 (2019)

13. X. Gong, J. Liu, Z. Sun, F. Li Journal of Testing and Evaluation 48, 5 JTE20180380 (2020)

14. T. Sun, T. Hu, G. Wang, Z. Shui, K. Ge, Q. Dai, Y. Xie Journal of Testing and Evaluation 48, 3 (2020)

15. Z.W. Cao, B. Liu, X.B. Li, D.Y. Li, L.J. Dong Geofluids UNSP 9218916 (2019)

16. L. Michalovicz, M.M.L. Muller, C.A. Tormena, W.A. Dick, M. Vicensi, L. Meert Archives of agronomy and soil science 65, 3385 (2019)

17. A.A. Karim, M. Kumar, S. Mohapatra, S.K. Singh, C.R. Panda Journal Of Material Cycles And Waste Management 21, 1, 107 (2019)

18. H. Farroukh, T. Mnif, F. Kamoun, L. Kamoun, F. Bennour Arabian Journal Of Geosciences. 11, 23, 760 (2018)

19. L. Fan, G. Chen, Z. Li, B. Lev, X. Zhou Advances in Intelligent Systems and Computing 1001, 261 (2020)

20. B.J. Yang, M.M. Yang, B.N. Wang, X.Y. Fang, Q. Wan Materials research express 6, 4, 045042 (2019)

21. M. Altiner, S. Top, B. Kaymakoglu, I.Y. Seckin, H. Vapur Journal of $\mathrm{CO}_{2}$ utilization 29, 117 (2019)

22. Y. Ennaciri, M. Bettach Materials and manufacturing processes 33, 16, 1727 (2018)

23. A. Telesca, M. Marroccoli, F. Winnefeld Advances in cement research 31, 3, 113 (2019)

24. M.I. Romero-Hermida, A.M. Borrero-Lopez, F.J. Alejandre, V. Flores-Ales, A. Santos, J.M. Franco, L. Esquivias Cement \& Concrete Composites 95, 205 (2019)

25. Y.F. Zhuang, T.Y. Li, P. Yuan, Y.Q. Li, Y.M. Yang, Z.P Yang. Applied physics a-materials science \& processing 125, 2141 (2019)

26. X.B. Tong, J.X. Yang, P.P. Wu, X.M. Zhang, Y.J. Seo Journal of alloys and compounds 779, 399 (2018) 